\title{
Superior Vena Cava Lymphoma
}

\author{
Fumiya Ogasawara $^{1}$, Yu Nakatani ${ }^{2}$ and Kensuke Kojima ${ }^{1}$
}

Key words: diffuse large B cell lymphoma, superior vena cava syndrome, thrombosis

(Intern Med 59: 1231, 2020)

(DOI: 10.2169/internalmedicine.4140-19)

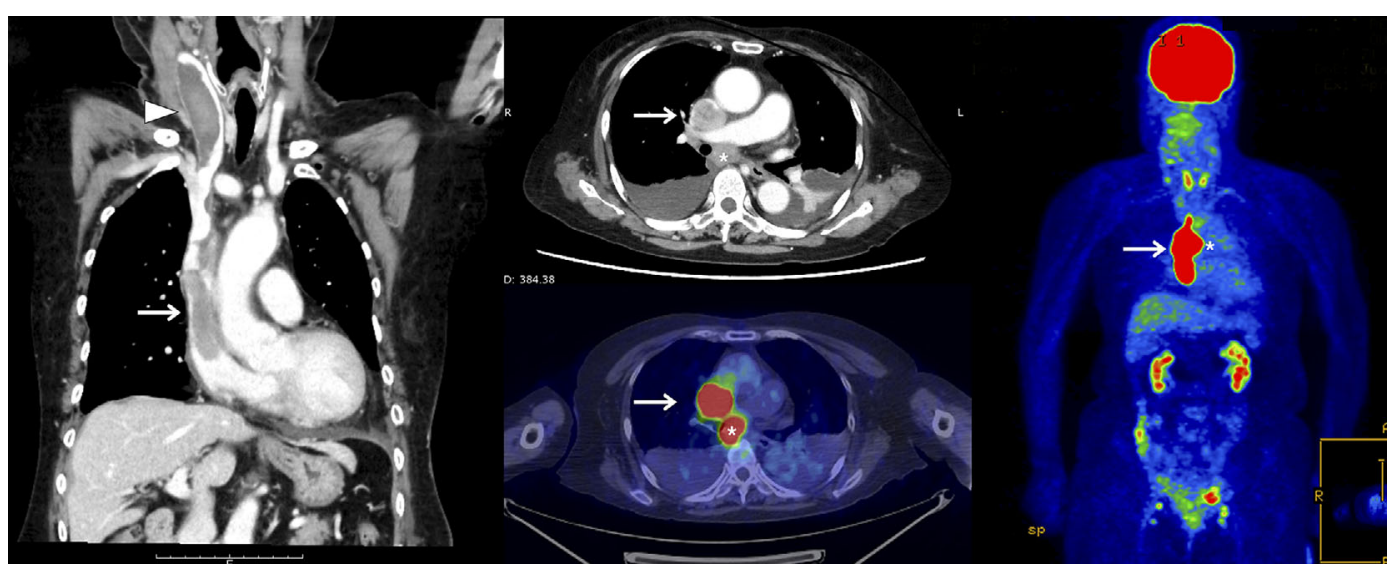

Picture.

A 71-year-old woman presented to the emergency department with a 2-month history of shortness of breath, nonproductive cough, and facial swelling. Lymphoma-associated B symptoms (fever, night sweats, and weight loss) were absent. Computed tomography showed a mass in the superior vena cava (SVC) along with right internal jugular vein thrombosis and bilateral non-malignant pleural effusions (Picture). The vascular lumen of the superior vena cava appeared to be intact. ${ }^{18} \mathrm{~F}$-Fluorodeoxyglucose (FDG) positron emission tomography showed an intense uptake in the SVC tumor. A biopsy specimen of the subcarinal lymph node revealed histologic features of diffuse large B cell lymphoma (DLBCL) with the GCB immunophenotype (CD20+CD10+ BCL6+MUM1-CD30-). She received R-CHOP chemotherapy (rituximab, cyclophosphamide, doxorubicin, vincristine, and prednisolone) along with warfarin, leading to the disappearance of the lymphoma lesions, pleural effusion, and internal jugular vein thrombosis. Our experience suggests the importance of an early lymphoma diagnosis with potentially life-threatening SVC syndrome $(1,2)$.
Written informed consent was obtained from the patient for publication.

The authors state that they have no Conflict of Interest (COI).

Fumiya Ogasawara and Yu Nakatani contributed equally to this work.

\section{References}

1. Nomori H, Nara S, Morinaga S, Soejima K. Primary malignant lymphoma of superior vena cava. Ann Thorac Surg 66: 14231424, 1998.

2. Nakamura S, Kagawa K, Sumitani R, et al. Primary CD30-positive diffuse large B-cell lymphoma in the superior vena cava. Intern Med 56: 2043-2047, 2017.

The Internal Medicine is an Open Access journal distributed under the Creative Commons Attribution-NonCommercial-NoDerivatives 4.0 International License. To view the details of this license, please visit (https://creativecommons.org/licenses/ by-nc-nd/4.0/).

\footnotetext{
${ }^{1}$ Department of Hematology, Kochi Medical School, Kochi University, Japan and ${ }^{2}$ Department of Respiratory Medicine and Allergology, Kochi Medical School, Kochi University, Japan

Received: November 6, 2019; Accepted: December 1, 2019; Advance Publication by J-STAGE: January 17, 2020

Correspondence to Dr. Kensuke Kojima, k-koji@kochi-u.ac.jp
}

(C) 2020 The Japanese Society of Internal Medicine. Intern Med 59: 1231, 2020 